\title{
Impact of renal function on eligibility for chemotherapy and survival in patients who have undergone radical nephro-ureterectomy
}

\author{
Evanguelos Xylinas ${ }^{1,5}$, Michael Rink ${ }^{1,7}$, Vitaly Margulis², Thomas Clozel', \\ Richard K. Lee', Evi Comploj ${ }^{8}$, Giacomo Novara', Jay D. Raman³, Yair Lotan², \\ Alon Weizer ${ }^{4}$, Morgan Roupret ${ }^{1,6}$, Armin Pycha ${ }^{8}$, Douglas S. Scherr', Christian Seitz ${ }^{11}$, \\ Vincenzo Ficarra', Quoc-Dien Trinh ${ }^{12}$, Pierre I. Karakiewicz ${ }^{12}$, Francesco Montorsi ${ }^{10}$, \\ Marc Zerbib ${ }^{5}$ and Shahrokh F. Shariat ${ }^{1}$ for the UTUC Collaboration
}

\begin{abstract}
'Department of Urology, Division of Medical Oncology (SFS), Weill Cornell Medical College, New York-Presbyterian Hospital, New York, NY, ${ }^{2}$ Department of Urology, University of Texas Southwestern Medical Center, Dallas, TX, ${ }^{3}$ Division of Urology, Penn State Milton S. Hershey Medical Center, Hershey, PA, ${ }^{4}$ Department of Urology, University of Michigan, Ann Arbor, MI, USA, ${ }^{5}$ Department of Urology Cochin Hospital, APHP, Paris Descartes University, ${ }^{6}$ Department of Urology, Pitie-Salpetriere Hospital, Assistance Publique Hôpitaux de Paris, Faculté de Médecine Pierre et Marie Curie, Paris, France, ${ }^{7}$ Department of Urology, University Medical Center Hamburg-Eppendorf, Hamburg, Germany, ${ }^{8}$ Department of Urology, General Hospital of Bolzano, Bolzano, ${ }^{9}$ Department of Urology, University of Padua, Padua, ${ }^{10}$ Department of Urology, Vita-Salute University, Milan, Italy, " Department of Urology, St. John of God Hospital, Teaching Hospital of the Medical University of Vienna, Vienna, Austria, and

${ }^{12}$ Department of Urology, University of Montreal, Montreal, QC, Canada
\end{abstract}

\section{What's known on the subject? and What does the study add?}

- Radical nephroureterectomy (RNU), the standard of care treatment for high-risk urothelial carcinoma of the upper tract (UTUC), results in loss of a renal unit. Loss of renal function decreases eligibility for systemic chemotherapies and results in decreased overall survival in various malignancies.

- The study shows that only a small proportion of patients had a preoperative renal function that would allow cisplatin-based chemotherapy. Moreover, eGFR significantly decreased after RNU, thereby lowering the rate of cisplatin eligibility to only 16 and $52 \%$ of patients based on the thresholds of 60 and $45 \mathrm{~mL} / \mathrm{min} / 1.73 \mathrm{~m}^{2}$, respectively. Taken together with the rest of the literature, the findings of the study support the use of cisplatin-based chemotherapy, when indicated, in the neoadjuvant rather than adjuvant setting.

\section{Objective}

- To report (i) the estimated glomerular filtration rate (eGFR) changes in patients undergoing radical nephro-ureterectomy (RNU) for upper tract urothelial carcinoma (UTUC); (ii) the rate of change in eGFR in patients eligible for cisplatin-based chemotherapy; and (iii) the association of preoperative, postoperative and rate of change of renal function variables with survival outcomes.

\section{Patient and Methods}

- We performed a retrospective analysis of 666 patients treated with RNU for UTUC at seven international institutions from 1994 to 2007.

- The eGFR was calculated at baseline and at 3-6 months (Modification of Diet in Renal Disease formula (MDRD) and Chronic Kidney Disease Epidemiology Collaboration formula (CKD-EP) equations).

\section{Results}

- The median (interquartile range) eGFR decreased by $18.2(8-12) \%$ after RNU. A total of $37 \%$ of patients had a preoperative $\mathrm{eGFR} \geq 60 \mathrm{~mL} / \mathrm{min} / 1.73 \mathrm{~m}^{2}$, which decreased to $16 \%$ after RNU $(P<0.001) ; 72 \%$ of patients had a preoperative eGFR $\geq 45 \mathrm{~mL} / \mathrm{min} /$ $1.73 \mathrm{~m}^{2}$, which decreased to $52 \%$ after RNU $(P<0.001)$. The distributions were similar when analyses were restricted to patients with locally advanced disease (pT3-pT4) and/or lymph node metastasis. Patients older than the median age of 70 years were more likely to have a decrease in eGFR after RNU $(P<0.001)$.

- None of the renal function variables was associated with clinical outcomes such as disease recurrence, cancer-specific and overall mortality; however, when analyses were restricted to patients who had no adjuvant 
chemotherapy and did not experience disease recurrence $(n=431)$, a preoperative eGFR $\geq 60 \mathrm{~mL} / \mathrm{min} / 1.73 \mathrm{~m}^{2}$ $(P=0.03)$ and a postoperative eGFR $\geq 45 \mathrm{~mL} / \mathrm{min} /$ $1.73 \mathrm{~m}^{2}(P=0.04)$ were associated with better overall survival in univariable analyses.

\section{Conclusions}

- In patients who had UTUC, eGFR was low and furthermore, it significantly decreased after RNU.
- Renal function did not affect cancer-specific outcomes after RNU.

\section{Keywords}

renal function, radical nephroureterectomy, upper tract urothelial carcinoma, chemotherapy

\section{Introduction}

Upper tract urothelial carcinoma (UTUC) is a relatively rare neoplasm accounting for 5-6\% of all urothelial tumours. Radical nephro-ureterectomy (RNU) with excision of the bladder cuff is the standard of care treatment for high-risk UTUC [1]. Despite its durable long-term disease control in patients with early stage disease, the 5 -year overall survival of patients with non-organ-confined UTUC is $<50 \%$, and for those with nodal metastasis, it is only $\sim 35 \%$ [2-4]. In patients whose disease is detected at a point where surgical cure is possible but risk of disease recurrence remains high $(\geq \mathrm{pT} 3$ and/or lymph node metastasis), chemotherapy has been considered as an option for adjuvant therapy [5-7]; however, the timing of chemotherapy in UTUC is in debate as surgical management of the disease, i.e. RNU, affects a patient's renal function and thereby eligibility for adjuvant chemotherapy. This strengthens the debate about neoadjuvant regimens $[8,9]$. Moreover, in other malignancies, such as RCC, the decrease in estimated GFR (eGFR) has been shown to negatively affect overall survival [10].

The aim of the present study was to report baseline eGFR and changes in patients undergoing RNU for UTUC. In addition, we wanted to report the effect of RNU on eligibility for cisplatin-based chemotherapy based on the change in eGFR. Finally, we evaluated the association of preoperative and postoperative renal function variables, as well as their rate of change, with oncological outcomes and overall survival.

\section{Patients and Methods \\ Patients}

In this institutional-review-board-approved study, all participating sites provided the necessary institutional data-sharing agreements before the initiation of the study. A total of seven centres worldwide provided data. A computerized databank was generated for data transfer. After combining the datasets, reports were generated for each variable to identify data inconsistencies and other data integrity problems. Through regular communication with all sites, resolution of all identified anomalies was achieved before analysis. Before the final analysis, the database was frozen and the final dataset was produced for the present analysis. From 1994 to 2007, 781 patients underwent RNU with bladder cuff excision for UTUC. None of patients received preoperative chemotherapy or radiotherapy. Adjuvant chemotherapy was administered at the clinicians' discretion based on tumour stage and overall health status as well as patient preference $(n=62)$. Patients in whom pre- and postoperative serum creatinine $(\mathrm{Scr})$ concentration data were not available were excluded from the analyses $(n=115,17.3 \%)$. These patients did not differ from the population of the study in terms of preoperative characteristics.

\section{Pathological Evaluation}

All surgical specimens were processed according to standard pathological procedures at each institution. Tumours were staged according to the 2002 American Joint Committee on Cancer/Union Internationale Contre le Cancer TNM classification [11]. Tumour grade was assessed according to the $1998 \mathrm{WHO} /$ International Society of Urologic Pathology consensus classification [12]. Histopathological assessment included concomitant carcinoma in situ, tumour architecture (papillary or sessile based on the predominant feature of the index lesion [13]), lymphovascular invasion (defined as the presence of tumour cells within an endothelium-lined space without underlying muscular walls [14]), and tumour necrosis (defined as the presence of microscopic coagulative necrosis in $>10 \%$ of the tumour [15]). Tumour location was defined as either renal pelvicalyceal or ureteric based on the index cancer [16]. Tumour multifocality was defined as the synchronous presence of two or more pathologically confirmed tumours in any location (renal pelvis or ureter) $[17,18]$.

\section{Follow-up}

Patients were generally followed every 3-4 months for the first year after RNU, every 6 months from the second to the 
fifth year, and annually thereafter. Follow-up consisted of a history, physical examination, routine blood work, urinary cytology, chest radiography, cystoscopic evaluation of the urinary bladder, and radiographic evaluation of the contralateral upper urinary tract. Elective bone scans, chest CT, or MRI were performed when clinically indicated.

Disease recurrence was defined as tumour relapse in the operative field, regional lymph nodes, and/or distant metastasis. Cause of death was determined by treating physicians, by chart review corroborated by death certificates, or by death certificates alone. To reduce bias in attribution of cause of death, only patients who had UTUC listed in the death certificate were considered to have died from UTUC for the present study [19]. All patients who were coded as dead from cancer had previous disease recurrence. Patients who died in the perioperative period (i.e. within 30 days of surgery) were censored at time of death for UTUC-specific survival analyses.

\section{Renal Function Variables}

We calculated eGFR at baseline and 3-6 months after RNU, using the MDRD $\left(\mathrm{GFR}\left[\mathrm{mL} / \mathrm{min} / 1.73 \mathrm{~m}^{2}\right]=175 \times\right.$ [Scr]-1.154 $\times$ [Age] $-0.203 \times[0.742$ if female $] \times[1.212$ if African]) [20] and chronic kidney disease (CKD)-EPI (GFR $=141 \mathrm{X}_{\min }[\mathrm{Scr} / \kappa, 1] \alpha \mathrm{X}_{\max }[\mathrm{Scr} / \kappa, 1]-1.209 \mathrm{X}$ 0.993Age $\mathrm{X}$ 1.018 [if female] X 1.159 [if black]) [21] equations. The two equations have been shown to have substantial agreement for baseline and follow-up eGFR [22]. We used the median value between the two equations (inter-equation coefficient variability of 0.94 and 0.96 for baseline and postoperative data, respectively). In addition, we calculated the absolute (eGFR follow-up $\left.-e G_{\text {baseline }}\right)$ and percent change in eGFR between preoperative and postoperative ([eGFR $\mathrm{e}_{\text {follow-up }}-$ $\left.\left.\mathrm{eGFR}_{\text {baseline }}\right]^{*} 100 / \mathrm{eGFR}_{\text {baseline }}\right)$. We also reported the preoperative and postoperative number of patients with an eGFR $\geq 60 \mathrm{~mL} / \mathrm{min}$ per $1.73 \mathrm{~m}^{2}$ and an eGFR $\geq$ $45 \mathrm{~mL} / \mathrm{min}$ per $1.73 \mathrm{~m}^{2}$, and also the changes in CKD stage. We chose an eGFR threshold of $60 \mathrm{~mL} / \mathrm{min}$ per $1.73 \mathrm{~m}^{2}$, which has traditionally defined eligibility for full-dose cisplatin therapy and a threshold of $45 \mathrm{~mL} / \mathrm{min}$ per $1.73 \mathrm{~m}^{2}$, which has been previously cited as a more strict definition of CKD and has been shown to be associated with a higher risk of comorbidities related to $\mathrm{CKD}$. We then assessed the impact of age (using the median age of our population as the threshold) on the rate of change in renal function after RNU.

\section{Statistical Analysis}

The Mann-Whitney $U$-test was used to compare non-parametric continuous variables and a chi-squared and Fisher's exact tests to compare nominal variables. Recurrence-free and cancer-specific and overall survival curves were generated using the Kaplan-Meier method and compared using the log-rank test. Univariable and multivariable Cox regression models addressed outcomes after RNU. All reported $P$-values are two-sided, and a $P$ value of 0.05 was considered to indicate statistical significance. Statistical analyses were performed with SPSS (v20.0, IBM Corp, NY, USA).

\section{Results}

\section{Clinicopathological Characteristics and Baseline} Renal Function

Overall 666 patients were included in the study. The median (interquartile range [IQR]) age at surgery was 70 (54-76) years. The clinical and pathological characteristics of the study population are shown in Table 1 . The preoperative and postoperative renal function characteristics of the 666 patients are shown in Table 2; 249 patients (37\%) had a preoperative eGFR $\geq 60 \mathrm{~mL} / \mathrm{min}$ per $1.73 \mathrm{~m}^{2}$ and $479(72 \%)$ had an eGFR $\geq 45 \mathrm{~mL} / \mathrm{min}$ per $1.73 \mathrm{~m}^{2}$. The preoperative CKD stage distribution was: CKD I $(n=32,5 \%)$, CKD II $(n=217,32.5 \%)$, CKD III $(n=$ $386,58 \%)$, CKD IV $(n=28,4 \%)$, and CKD V $(n=3,0.4 \%)$.

\section{Postoperative Renal Function and Rates of Change}

After RNU, 105 patients (16\%) had a postoperative eGFR $\geq$ $60 \mathrm{~mL} / \mathrm{min}$ per $1.73 \mathrm{~m}^{2}$ and $345(52 \%)$ had an eGFR $\geq$ $45 \mathrm{~mL} / \mathrm{min}$ per $1.73 \mathrm{~m}^{2}$ (Table 2). The postoperative CKD stages distribution was: CKD I $(n=7,1 \%)$, CKD II $(n=98$, $15 \%)$, CKD III $(n=460,69 \%)$, CKD IV $(n=91,13.5 \%)$ and CKD V $(n=10,1.5 \%)$. Comparison of preoperative and postoperative Scr levels for each patient showed a mean difference of $0.32 \mathrm{mg} / \mathrm{dL}(P<0.001$; Table 2$)$, which represents a median (IQR) increase of $24.8(10-34) \%$. On similar analysis performed for eGFR, we found a mean difference between preoperative and postoperative eGFR of $10.2 \mathrm{~mL} / \mathrm{min}$ per $1.73 \mathrm{~m}^{2}(P<0.001)$, which represents a median (IQR) decrease of $18.2(8-12) \%$.

\section{Preoperative, Postoperative and Rates of Change of Renal Function Stratified by pT Stage and Lymph Node Status}

There was no difference either in terms of preoperative eGFR between organ-confined and non-organ-confined UTUC ( 57.3 vs $55.4, P=0.73$ ), nor in terms of postoperative eGFR ( 46.3 vs $46.5, P=0.19)$. The same was true for lymph node status $(P=0.43$ and $P=0.53$, respectively). $27.5 \%$ of patients with locally advanced disease (pT3-pT4) and $32 \%$ of patients with $\mathrm{pN}+$ stage had a preoperative eGFR $\geq 60 \mathrm{~mL} / \mathrm{min}$ per $1.73 \mathrm{~m}^{2}$, a proportion that fell to 15 and $25 \%$, respectively, after RNU. 
Table 1 Clinicopathological characteristics of 666 patients treated with RNU for UTUC.

\begin{tabular}{|c|c|}
\hline Median, IQR age, years & $69.6(54-76)$ \\
\hline \multicolumn{2}{|l|}{ Gender, $n(\%)$} \\
\hline Male & $441(66)$ \\
\hline Female & $225(34)$ \\
\hline \multicolumn{2}{|l|}{ Body mass index, $\mathrm{kg} / \mathrm{m}^{2}$} \\
\hline Mean (SD) & $28.5(5.5)$ \\
\hline Median (IQR) & $28.2(24-32)$ \\
\hline \multicolumn{2}{|c|}{ ECOG performance status, $n(\%)$} \\
\hline 0 & $445(67)$ \\
\hline $1-3$ & $221(33)$ \\
\hline \multicolumn{2}{|c|}{ Previous bladder cancer, $n(\%)$} \\
\hline Yes & $244(37)$ \\
\hline No & $422(63)$ \\
\hline \multicolumn{2}{|c|}{ Primary tumour location, $n(\%)$} \\
\hline Renal pelvis & $420(63)$ \\
\hline Ureteral & $246(37)$ \\
\hline \multicolumn{2}{|l|}{ Multifocality, $n(\%)$} \\
\hline Yes & $164(25)$ \\
\hline No & $502(75)$ \\
\hline \multicolumn{2}{|l|}{ Surgical approach, $n(\%)$} \\
\hline Open & $519(78)$ \\
\hline Laparoscopic & $147(22)$ \\
\hline \multicolumn{2}{|l|}{ pT stage, $n(\%)$} \\
\hline pT0-pTa-pTis-pT1 & $326(49)$ \\
\hline pT2 & $118(18)$ \\
\hline рT3 & $182(27)$ \\
\hline pT4 & $40(6)$ \\
\hline \multicolumn{2}{|l|}{ Grade, $n(\%)$} \\
\hline No Tumour & $12(2)$ \\
\hline Low & $121(18)$ \\
\hline High & $533(80)$ \\
\hline \multicolumn{2}{|l|}{ Lymph node status, $n$ (\%) } \\
\hline $\mathrm{pN} 0$ & $291(44)$ \\
\hline $\mathrm{pNx}$ & $291(44)$ \\
\hline $\mathrm{pN}+$ & $84(12)$ \\
\hline \multicolumn{2}{|c|}{ Concomitant carcinoma in situ, $n$ (\%) } \\
\hline Present & $229(34)$ \\
\hline Absent & $437(66)$ \\
\hline \multicolumn{2}{|c|}{ Lymphovascular invasion ${ }^{*}, n(\%)$} \\
\hline Present & $171(31)$ \\
\hline Absent & $380(69)$ \\
\hline \multicolumn{2}{|c|}{ Adjuvant chemotherapy, $n$ (\%) } \\
\hline Yes & $62(9)$ \\
\hline No & $604(91)$ \\
\hline
\end{tabular}

ECOG, European Cooperative Oncology Group. ${ }^{*}$ Lymphovascular invasion information was available only in 551 patients (83\%).

Similarly, $69 \%$ patients with locally advanced disease (pT3-pT4) and $66 \%$ of patients with pN+ stage disease had a preoperative eGFR $\geq 45 \mathrm{~mL} / \mathrm{min}$ per $1.73 \mathrm{~m}^{2}$, falling to 52 and $61 \%$, respectively, after RNU. Finally, when combining patients with pT3-pT4 and/or pN+ disease $(n=$ 238 ), only $17.5 \%$ had a postoperative eGFR $\geq 60$ and $54.5 \%$ had a postoperative eGFR $\geq 45 \mathrm{~mL} / \mathrm{min}$ per $1.73 \mathrm{~m}^{2}$.

\section{Preoperative, postoperative and rates of change of renal function stratified by patient's age at surgery}

The median age at surgery was 70 years and was chosen as a threshold to stratify renal function (Table 2). Younger patients ( $<70$ years) were more likely to have a preoperative eGFR $\geq 60$ ( 44 vs $31 \% ; P<0.001$ ) and $\geq 45 \mathrm{~mL} / \mathrm{min}$ per $1.73 \mathrm{~m}^{2}(79$ vs $66 \% ; P<0.001)$ compared with patients $\geq$ 70 years. eGFR decreased significantly after surgery in both age groups; however, younger patients were also more likely to maintain an eGFR $\geq 60$ ( 21 vs $11 \%, P<0.001$ ) and $\geq 45 \mathrm{~mL} / \mathrm{min}$ per $1.73 \mathrm{~m}^{2}$ (61 vs $43 \%, P<0.001$ ).

\section{Association of eGFR (Preoperative and Postoperative) and Rates of Change with Clinical Outcomes}

At a median (IQR) follow-up of 45.5 (24-67) months, 212 patients (32\%) experienced disease recurrence, 163 (24.5\%) died from UTUC and 104 (15.5\%) from other causes. We addressed the association between renal function variables (preoperative and postoperative eGFR as a continuous variable or using thresholds of 60 and $45 \mathrm{~mL} / \mathrm{min}$ per $1.73 \mathrm{~m}^{2}$, and the rates of change either continuous or change in categorization) with disease recurrence, cancer-specific and overall mortality. None of these variables was associated with outcomes in univariable analyses. Similarly, when restricting the analyses to patients who did not experience disease recurrence, none of the renal function variables was associated with overall survival. The same was true when patients were stratified by an age threshold of 70 years, but when analyses were restricted to patients who had no adjuvant chemotherapy and who did not experience disease recurrence $(n=431)$, a preoperative eGFR $\geq$ $60 \mathrm{~mL} / \mathrm{min}$ per $1.73 \mathrm{~m}^{2}(P=0.03$, hazard ratio [HR]: 0.64 , CI: $0.42-0.97)$ and a postoperative eGFR $\geq 45 \mathrm{~mL} / \mathrm{min}$ per $1.73 \mathrm{~m}^{2}(P=0.04$, HR: 0.67, CI: $0.45-0.99)$ were associated with better overall survival in univariable analyses (Fig. 1A and B). These factors were not independently associated with overall survival in multivariable analyses which adjusted for standard clinico-pathological features $(P=0.72, \mathrm{HR}: 1.11, \mathrm{CI}$ : $0.59-2.10$ and $P=0.11$, HR: 0.61, CI: $0.33-1.13$ ).

\section{Discussion}

We confirmed that eGFR decreases significantly after RNU $[8,9]$. We found an $18 \%$ decrease in eGFR after RNU, which was similar to the rates reported in previous studies $(22-24 \%)[8,9]$. This rate of decrease was independent of the pathological features. Younger patients ( $<70$ years) were more likely to have a better preoperative eGFR and to maintain it postoperatively than older patients ( $\geq 70$ years). This is in contrast to the findings of Kaag et al. [9] who did not find a statistically significant difference between age categories. The differences between that and the present study are probably attributable to differences in samples size and patient characteristics such as age distribution. 
Table 2 Baseline and postoperative renal function of the 666 patients treated with RNU for UTUC.

\begin{tabular}{|c|c|c|c|}
\hline & Preoperative & Postoperative & $\boldsymbol{P}$ \\
\hline $\mathrm{SCr}, \mathrm{mg} / \mathrm{dL}$ & & & $<0.001$ \\
\hline Mean (SD) & $1.29(0.48)$ & $1.61(1.2)$ & \\
\hline Median (IQR) & $1.20(1-1.5)$ & $1.3(1-2)$ & \\
\hline \multicolumn{4}{|l|}{ eGFR $\mathrm{mL} / \mathrm{min}$ per $1.73 \mathrm{~m}^{2}$} \\
\hline MDRD & & & $<0.001$ \\
\hline Mean (SD) & $56.1(18.4)$ & $45.9(15.8)$ & \\
\hline Median (IQR) & $54.8(43-66)$ & $45.5(35-54)$ & \\
\hline CDK-EPI & & & $<0.001$ \\
\hline Mean (SD) & $57.2(18.4)$ & $46.8(16.9)$ & \\
\hline Median (IQR) & $55(44-69)$ & $46(35-57)$ & \\
\hline eGFR(MDRD+CDK-EPI)/2 & & & $<0.001$ \\
\hline Mean (SD) & $56.6(18)$ & $46.3(16.3)$ & \\
\hline Median (IQR) & $56.1(43-68)$ & $45.9(35-55)$ & \\
\hline eGFR $\geq 60 \mathrm{~mL} / \mathrm{min}$ per $1.73 \mathrm{~m} 2 \mathrm{pT}$ stage, $n(\%)$ & $249(37)$ & $105(16)$ & $<0.001$ \\
\hline pT stage, $n(\%)$ & & & $<0.001$ \\
\hline pT0-pTis-pTa-pT1 & $138(56)$ & $60(57)$ & \\
\hline pT2 & $40(16)$ & $12(11)$ & \\
\hline рT3 & $53(21)$ & $25(24)$ & \\
\hline pT4 & $18(7)$ & $8(8)$ & \\
\hline Lymph node status, $n$ (\%) & & & $<0.001$ \\
\hline $\mathrm{pNx}$ & $119(48)$ & $45(43)$ & \\
\hline pNO & $103(41)$ & $39(37)$ & \\
\hline $\mathrm{pN}+$ & $27(11)$ & $21(20)$ & \\
\hline eGFR $\geq 45 \mathrm{~mL} / \mathrm{min}$ per $1.73 \mathrm{~m}^{2}, n(\%)$ & $479(72)$ & $345(52)$ & $<0.001$ \\
\hline pT stage, $n(\%)$ & & & $<0.001$ \\
\hline pT0-pTis-pTa-pT1 & $240(50)$ & $172(50)$ & \\
\hline pT2 & $87(18)$ & $57(16)$ & \\
\hline рT3 & $124(26)$ & $92(27)$ & \\
\hline pT4 & $28(6)$ & $24(7)$ & \\
\hline Lymph node status & & & $<0.001$ \\
\hline $\mathrm{pNx}$ & $216(45)$ & $141(41)$ & \\
\hline pNo & $208(43)$ & $153(44)$ & \\
\hline $\mathrm{pN}+$ & $55(12)$ & $51(15)$ & \\
\hline \multicolumn{4}{|l|}{$\geq 70$ years old } \\
\hline $\mathrm{SCr}, \mathrm{mg} / \mathrm{dL}$ & & & $<0.001$ \\
\hline Mean (SD) & $1.29(0.42)$ & $1.61(1.15)$ & \\
\hline eGFR $\mathrm{mL} / \mathrm{min}$ per $1.73 \mathrm{~m}^{2}$ & & & $<0.001$ \\
\hline Mean (SD) & $52.9(16.9)$ & $43.5(15.2)$ & \\
\hline eGFR $\geq 60 \mathrm{~mL} / \mathrm{min}$ per $1.73 \mathrm{~m}^{2}, n(\%)$ & $107(31)$ & $36(11)$ & $<0.001$ \\
\hline eGFR $\geq 45 \mathrm{~mL} / \mathrm{min}$ per $1.73 \mathrm{~m}^{2}, n(\%)$ & $225(66)$ & $148(43)$ & $<0.001$ \\
\hline \multicolumn{4}{|l|}{$<70$ years old } \\
\hline $\mathrm{SCr}, \mathrm{mg} / \mathrm{dL}$ & & & $<0.001$ \\
\hline Mean (SD) & $1.29(0.55)$ & $1.61(1.26)$ & \\
\hline \multicolumn{4}{|l|}{ Median (IQR) } \\
\hline eGFR mL/min per $1.73 \mathrm{~m}^{2}$ & & & $<0.001$ \\
\hline Mean (SD) & $60.6(19)$ & $49.4(16.8)$ & \\
\hline \multicolumn{4}{|l|}{ Median (IQR) } \\
\hline eGFR $\geq 60 \mathrm{~mL} / \mathrm{min}$ per $1.73 \mathrm{~m}^{2}, n(\%)$ & $142(44)$ & $69(21)$ & $<0.001$ \\
\hline eGFR $\geq 45 \mathrm{~mL} / \mathrm{min}$ per $1.73 \mathrm{~m}^{2}, n(\%)$ & $255(79)$ & $198(61)$ & $<0.001$ \\
\hline
\end{tabular}

We found that only a small proportion of patients with high-risk UTUC were eligible for adjuvant chemotherapy based on eGFR. Moreover, the rate of eligibility decreased dramatically after RNU. The role and benefit of adjuvant chemotherapy for locally advanced and/or lymph-node-positive UTUC remains controversial [23]. Although a small single-centre retrospective series reported a benefit in overall survival in 32 patients [5], two retrospective international studies could not confirm these results $(n=121$ and $n=143)[6,7]$. By contrast, two retrospective studies using systemic chemotherapy in the neoadjuvant setting ( $n=107$ and $n=82)$ found a $14-15 \%$ complete remission (pT0) rate $[24,25]$. Extrapolating from lower tract urothelial carcinoma, and based on cumulative evidence, the neoadjuvant setting seems the most effective way of administrating systemic cisplatin-based chemotherapy in UTUC $[26,27]$. This is even more important in UTUC because eligibility for cisplatin-based chemotherapy is heavily based on renal function, which decreases after RNU $[8,9]$. We chose an eGFR threshold of $60 \mathrm{~mL} / \mathrm{min}$ per $1.73 \mathrm{~m}^{2}$, which has traditionally defined eligibility for full-dose cisplatin therapy and also represents 
A

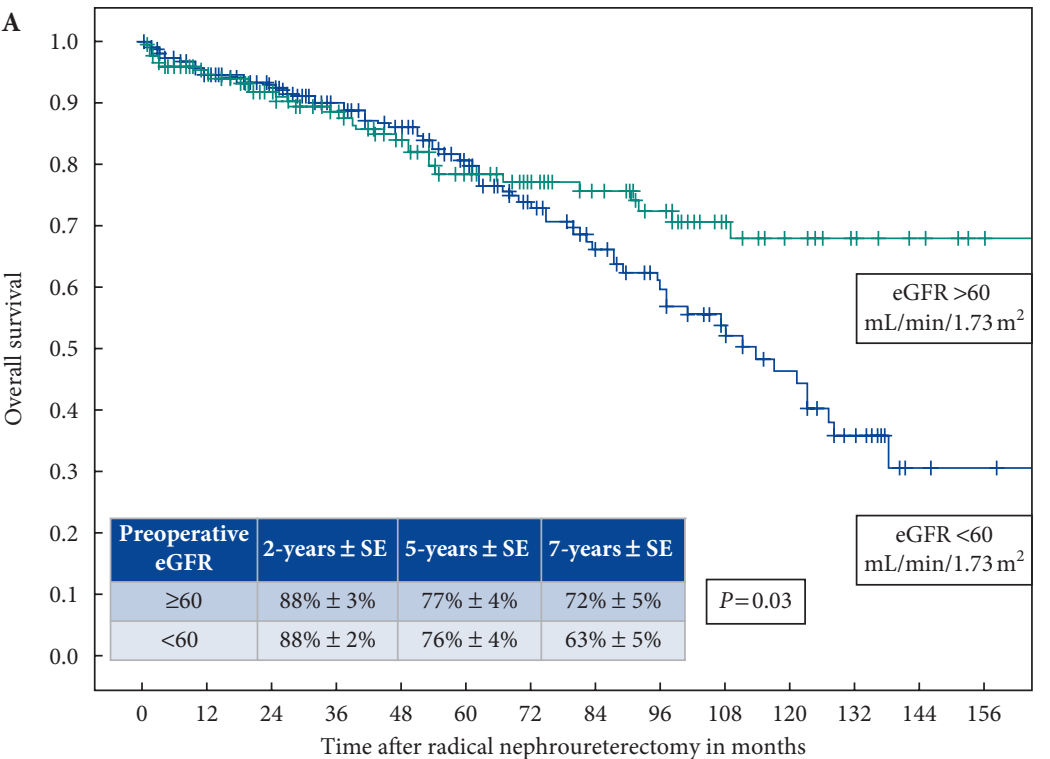

Fig. 1 A, Overall survival in patients without adjuvant chemotherapy and who did not experience disease recurrence. B, Overall survival in patients without adjuvant chemotherapy and who did not experience disease recurrence.

\begin{tabular}{l|cccccccccccccccc} 
& \multicolumn{10}{|c}{ Patient numbers at risk for overall survival } \\
\hline Months & 0 & 12 & 24 & 36 & 48 & 60 & 72 & 84 & 96 & 108 & 120 & 132 & 144 & 156 \\
Preoperative eGFR & 175 & 140 & 118 & 101 & 82 & 67 & 56 & 50 & 42 & 28 & 20 & 14 & 10 & 6 \\
$\geq 60 \mathrm{~mL} / \mathrm{min} / 1.73 \mathrm{~m}^{2}$ \\
\hline $\begin{array}{l}\text { Preoperative eGFR } \\
<60 \mathrm{~mL} / \mathrm{min} / 1.73 \mathrm{~m}^{2}\end{array}$ & 256 & 218 & 180 & 143 & 122 & 100 & 74 & 56 & 44 & 31 & 23 & 13 & 4 & 3
\end{tabular}

B

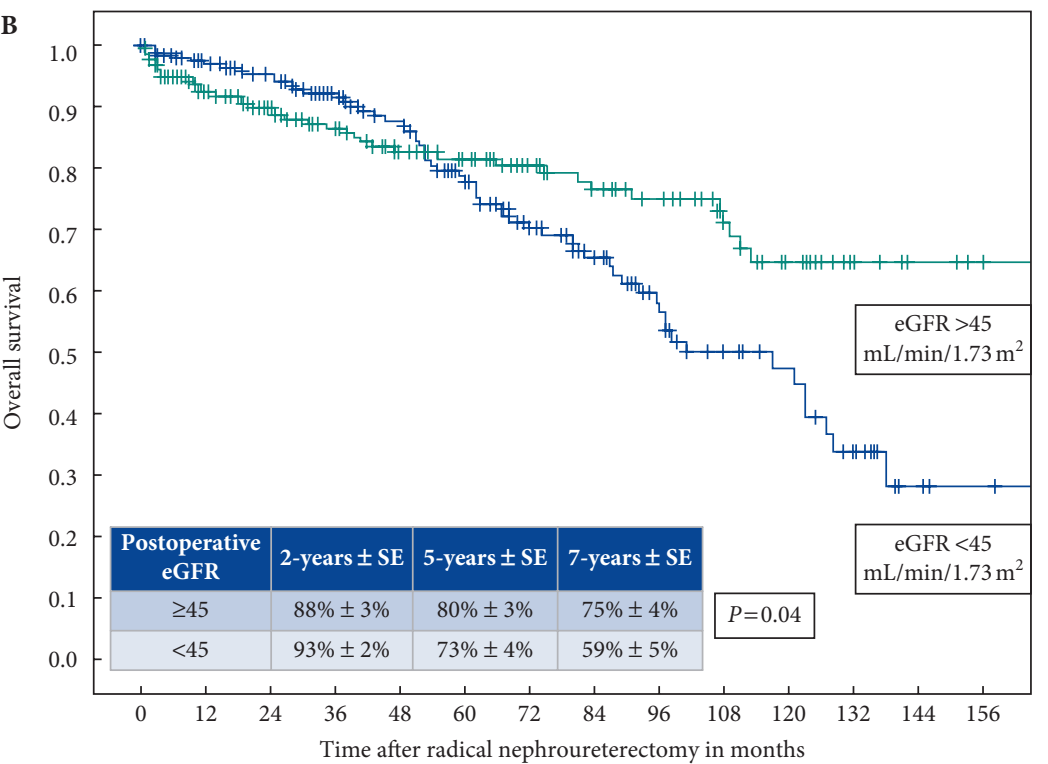

\begin{tabular}{l|cccccccccccccccc} 
& \multicolumn{11}{|c}{ Patient numbers at risk for overall survival } \\
\hline Months & 0 & 12 & 24 & 36 & 48 & 60 & 72 & 84 & 96 & 108 & 120 & 132 & 144 & 156 \\
$\begin{array}{l}\text { Postoperative eGFR } \\
\geq 45 \mathrm{~mL} / \mathrm{min} / 1.73 \mathrm{~m}^{2}\end{array}$ & 217 & 175 & 142 & 117 & 93 & 77 & 64 & 56 & 49 & 36 & 25 & 16 & 10 & 7 \\
$\begin{array}{l}\text { Postoperative eGFR } \\
<45 \mathrm{~mL} / \mathrm{min} / 1.73 \mathrm{~m}^{2}\end{array}$ & 214 & 183 & 156 & 127 & 111 & 90 & 66 & 50 & 37 & 23 & 18 & 11 & 4 & 2 \\
\end{tabular}

the transition into stage III CKD, and a threshold of $45 \mathrm{~mL} / \mathrm{min}$ per $1.73 \mathrm{~m}^{2}$, which has been previously cited as a more strict definition of CKD and has been shown to be associated with a higher risk of comorbidities related to
CKD [28]. Based on the eGFR threshold of $60 \mathrm{~mL} / \mathrm{min}$ per $1.73 \mathrm{~m}^{2}, 37 \%$ of patients were eligible for neoadjuvant cisplatin-based chemotherapy and only $16 \%$ were candidates for adjuvant chemotherapy. With the threshold 
of $45 \mathrm{~mL} / \mathrm{min}$ per $1.73 \mathrm{~m}^{2}, 72 \%$ of patients were eligible for neoadjuvant cisplatin-based chemotherapy while only $52 \%$ were candidates for adjuvant chemotherapy. Thus, in addition to possible associated reasons, the decrease in eGFR after RNU supports the use of cisplatin-based chemotherapy for high-risk UTUC in a neoadjuvant rather than adjuvant setting. The pertinent and remaining question is the identification of candidates for systemic chemotherapy [2] but, even more so than in bladder urothelial carcinoma, deficiencies in clinical staging make the accurate identification of patients who have advanced disease and are therefore the best candidates for systemic chemotherapy extremely difficult.

We did not find any association between eGFR, irrespective of categorization of the data, with oncological outcomes and overall survival. CKD has been associated with a significant increase in cardiovascular events and death from any cause, independently of competing comorbidities [28]. In RCC, a decrease in eGFR has been associated with overall survival $[10,29,30]$, but in the present study, renal function features (preoperative, postoperative and rate of change) were not associated with recurrence-free and cancer-specific survival, probably owing to the fact that cancer features had a stronger effect on outcomes. The lack of association with overall survival could be attributable to the short follow-up (45 months) of patients who did not succumb to their UTUC; however, when excluding from the analyses patients who experienced disease recurrence and those who underwent adjuvant chemotherapy, a preoperative $\mathrm{eGFR} \geq 60$ and a postoperative eGFR $\geq$ $45 \mathrm{~mL} / \mathrm{min}$ per $1.73 \mathrm{~m}^{2}$ were associated with overall survival. Larger cohorts with longer follow-up in patients who do not succumb to their disease are necessary to fully assess the association of eGFR with overall survival in patients who underwent RNU.

The present study has several limitations, including those inherent to a retrospective multicentre study design. We did not perform a centralized pathological review, which could have led to misinterpretations of pathological features. We used eGFR rather than creatinine clearance. Although patients with CKD stage 5 were present in the study, patients with comorbidities and/or CKD preoperatively may have been preferentially selected for conservative management. We acknowledge that medical comorbidities (e.g. hypertension and diabetes mellitus) could affect the renal function of these patients. Unfortunately, information on comorbidities was not available in our database, so we were unable to include this in the present analyses. In addition, the short follow-up and low number of non-cancer-specific events may have limited the statistical significance of some analyses.
In conclusion, only a small proportion of patients had a preoperative renal function that would allow cisplatin-based chemotherapy. Furthermore, eGFR significantly decreased after RNU, thereby lowering the rate of cisplatin eligibility to only 16 and $52 \%$ of patients, based on the thresholds of 60 and $45 \mathrm{~mL} / \mathrm{min}$ per $1.73 \mathrm{~m}^{2}$, respectively. Older patients ( $\geq 70$ years) had a lower baseline eGFR than younger patients and older patients ( $\geq 70$ years) had a proportionally higher rate of decrease in eGFR after RNU. Neither preoperative nor postoperative eGFR variables affected cancer-specific and overall survival outcomes after RNU. Taken together with the rest of the literature, the present findings support the use of cisplatin-based chemotherapy, when indicated, in the neoadjuvant rather than adjuvant setting.

\section{Conflict of Interest}

None declared.

\section{References}

1 Rouprêt M, Zigeuner R, Palou J et al. European guidelines for the diagnosis and management of upper urinary tract urothelial cell carcinomas: 2011 update. Eur Urol 2011; 59: 584-94

2 Margulis V, Shariat SF, Matin SF et al. Outcomes of radical nephroureterectomy: a series from the Upper Tract Urothelial Carcinoma Collaboration. Cancer 2009; 115: 1224-33

3 Roscigno M, Shariat SF, Margulis V et al. Impact of lymph node dissection on cancer specific survival in patients with upper tract urothelial carcinoma treated with radical nephroureterectomy. J Urol 2009; 181: 2482-9

4 Abouassaly R, Alibhai SM, Shah N, Timilshina N, Fleshner N, Finelli A. Troubling outcomes from population-level analysis of surgery for upper tract urothelial carcinoma. Urology 2010; 76: 895-901

5 Kwak C, Lee SE, Jeong IG, Ku JH. Adjuvant systemic chemotherapy in the treatment of patients with invasive transitional cell carcinoma of the upper urinary tract. Urology 2006; 68: 53-7

6 Hellenthal NJ, Shariat SF, Margulis V et al. Adjuvant chemotherapy for high risk upper tract urothelial carcinoma: results from the Upper Tract Urothelial Carcinoma Collaboration. J Urol 2009; 182: 900-6

7 Vassilakopoulou M, de la Motte Rouge T, Colin P et al. Outcomes after adjuvant chemotherapy in the treatment of high-risk urothelial carcinoma of the upper urinary tract (UUT-UC): results from a large multicenter collaborative study. Cancer 2011; 117: $5500-8$ 
8 Lane BR, Smith AK, Larson BT et al. Chronic kidney disease after nephroureterectomy for upper tract urothelial carcinoma and implications for the administration of perioperative chemotherapy. Cancer 2010; 116: 2967-73

9 Kaag MG, O'Malley RL, O'Malley P et al. Changes in renal function following nephroureterectomy may affect the use of perioperative chemotherapy. Eur Urol 2010; 58: 581-7

10 Thompson RH, Boorjian SA, Lohse CM et al. Radical nephrectomy for pTla renal masses may be associated with decreased overall survival compared with partial nephrectomy. J Urol 2008; 179: 468-71

11 Greene FL, Balch CM, Fleming ID et al. AJCC Cancer Staging Handbook: TNM Classification of Malignant Tumors, 6th edn. Chicago, IL: American Joint Committee on Cancer, 2002

12 Epstein JI, Amin MB, Reuter VR, Mostofi FK. The World Health Organization / International Society of Urological Pathology consensus classification of urothelial (transitional cell) neoplasms of the urinary bladder. Bladder Consensus Conference Committee. Am J Surg Pathol 1998; 22: 1435-48

13 Remzi M, Haitel A, Margulis V et al. Tumour architecture is an independent predictor of outcomes after nephroureterectomy: a multi-institutional analysis of 1363 patients. BJU Int 2009; 103: 307-11

14 Novara G, Matsumoto K, Kassouf W et al. Prognostic role of lymphovascular invasion in patients with urothelial carcinoma of the upper urinary tract: an international validation study. Eur Urol 2010; 57: 1064-71

15 Zigeuner R, Shariat SF, Margulis V et al. Tumour necrosis is an indicator of aggressive biology in patients with urothelial carcinoma of the upper urinary tract. Eur Urol 2010; 57: 575-81

16 Raman JD, Ng CK, Scherr DS et al. Impact of tumor location on prognosis for patients with upper tract urothelial carcinoma managed by radical nephroureterectomy. Eur Urol 2010; 57: 1072-9

17 Ouzzane A, Colin P, Xylinas E et al. Ureteral and multifocal tumours have worse prognosis than renal pelvic tumours in urothelial carcinoma of the upper urinary tract treated by nephroureterectomy. Eur Urol 2011; 60: 1258-65

18 Chromecki TF, Cha EK, Fajkovic $\mathrm{H}$ et al. The impact of tumor multifocality on outcomes in patients treated with radical nephroureterectomy. Eur Urol 2012; 61: 245-53

19 Rink M, Fajkovic H, Cha EK et al. Death Certificates Are Valid for the Determination of Cause of Death in
Patients With Upper and Lower Tract Urothelial Carcinoma. Eur Urol 2012; 61: 854-5

20 Levey AS, Bosch JP, Lewis JB et al. A more accurate method to estimate glomerular filtration rate from serum creatinine: a new prediction equation. Ann Intern Med 1999; 130: 461-70

21 Levey AS, Stevens LA, Schmid CH et al. A new equation to estimate glomerular filtration rate. Ann Intern Med 2009; 150: 604-12

22 Shikanov S, Clark MA, Raman JD et al. Chronic Kidney Disease Epidemiology Collaboration versus Modification of Diet in Renal Disease equations for renal function evaluation in patients undergoing partial nephrectomy. J Urol 2010; 184: 1867-71

23 Chromecki TF, Bensalah K, Remzi M et al. Prognostic factors for upper urinary tract urothelial carcinoma. Nat Rev Urol 2011; 8: 440-7

24 Matin SF, Margulis V, Kamat A et al. Incidence of downstaging and complete remission after neoadjuvant chemotherapy for high-risk upper tract transitional cell carcinoma. Cancer 2010; 116: 3127-34

25 Rajput MZ, Kamat AM, Clavell-Hernandez J et al. Perioperative outcomes of laparoscopic radical nephroureterectomy and regional lymphadenectomy in patients with upper urinary tract urothelial carcinoma after neoadjuvant chemotherapy. Urology 2011; 78: 61-7

26 Advanced Bladder Cancer (ABC) Meta-analysis Collaboration. Neoadjuvant chemotherapy in invasive bladder cancer: update of a systematic review and meta-analysis of individual patient data advanced bladder cancer (ABC) meta-analysis collaboration. Eur Urol 2005; 48: 202-5

27 Advanced Bladder Cancer (ABC) Meta-analysis Collaboration. Adjuvant chemotherapy in invasive bladder cancer: a systematic review and meta-analysis of individual patient data advanced bladder cancer (ABC) meta-analysis collaboration. Eur Urol 2005; 48: 189-99

28 Castro AF, Coresh J. CKD surveillance using laboratory data from the population-based National Health and Nutrition Examination Survey (NHANES). Am J Kidney Dis 2009; 53: 46-55

29 Patard JJ, Pantuck AJ, Crepel M et al. Morbidity and clinical outcome of nephron-sparing surgery in relation to tumour size and indication. Eur Urol 2007; 52: 148-54

30 Van Poppel H, Da Pozzo L, Albrecht W et al. A prospective, randomised EORTC intergroup phase 3 study comparing the oncologic outcome of elective nephron-sparing surgery and radical nephrectomy for low-stage renal cell carcinoma. Eur Urol 2011; 59: 543-52 
Correspondence: Shahrokh F. Shariat, Weill Cornell Medical College-New York-Presbyterian Hospital, 525 East $68^{\text {th }}$ St., Starr 900 New York, NY 10065, USA.

e-mail: sfshariat@gmail.com

Abbreviations: eGFR, estimated GFR; RNU, radical nephro-ureterectomy; UTUC, upper tract urothelial carcinoma; Scr, serum creatinine; MDRD, modification of diet in renal disease formula; CKD, chronic kidney disease; EPI, chronic kidney disease epidemiology collaboration formula; IQR, interquartile range; $\mathrm{HR}$, hazard ratio. 